\title{
Lojistik ve Tedarik Zinciri Süreçlerinde Büyük Veri Kullanımı ve Etkilerinin Analizi
}

\section{Utilization of The Big Data in The Logistics and Supply Chain Processes and Analysis of Its Impacts}

İsmail İyigün a,*

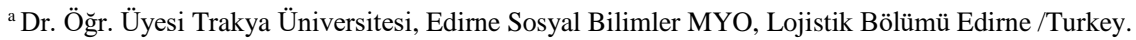
ORCID: 0000-0003-3841-0649

\section{MAKALE BİLGİSI}

\section{Makale Geçmişi:}

Başvuru tarihi: 11 Haziran 2019

Düzeltme tarihi: 26 Ekim 2019

Kabul tarihi: 01 Kasım 2019

\section{Anahtar Kelimeler:}

Büyük Veri

Lojistik

Tedarik Zinciri Teknolojisi

Endüstri 4.0

Nesnelerin İnterneti

\section{A R T I CLE INFO}

\section{Article history:}

Received 11 June 2019

Received in revised form 26 October 2019

Accepted 01 November 2019

\section{Keywords:}

Big Data

Logistics

Supply Chain Technology

Industry 4.0

Internet of Things
ÖZ

Günümüzde insanlık artık fiziksel veri depolama unsurlarına bağımlı değildir. Her geçen gün artan bir biçimde verilerin toplandığı ve büyük veri "Big Data" adı verilen devasa bir sistem bu gereksinimi ortadan kaldıracak gibi görünmektedir. Lojistik süreçlerin yapısal olarak karmaşıklık düzeyinin yüksek olması ve bir takım değişkenlerin operasyonların performansına önemli ölçüde etki etmesi lojistik süreçlerin optimize edilmesine yönelik olarak veri gereksinimini hayati düzeyde önemli hale getirmiştir. Dolayısıyla Büyük Veri’nin yakın bir gelecekte lojistik süreçler için vazgeçilmez bir role sahip olacağı öngörülebilmektedir. Bu çalışma Büyük Veri'nin lojistik süreçler üzerinde meydana getirebileceği etkiler ile yaratacağı faydalar ve risklerini analiz etmeye çalışmaktadır. Çalışma aynı zamanda Büyük Veri kullanımı sayesinde toplam faydayı artırabilecek, risk ve maliyetleri azaltabilecek bir takım yöntem ve uygulamaları önermektedir.

\section{A B S T R A C T}

Nowadays, humans are not dependent to the physical data storage elements. It can be seen that a gigantic system that called as the big data that collected the data increasingly each passing day can remove this requirement. Being extremely complex of the logistics systems and being significant impacts of a number of variables to the performance of logistics activities has made more important the data requirements in order to create the optimal logistics operations. Therefore, it can be seen that the Big Data will have an indispensable role in logistics processes in the near future. This study tried to analyze the impacts on logistics processes as well as its benefits and risks. At the same time, this paper also suggests a number of methods and applications that can increase the total benefits while the costs and risks are reduced.

\section{Giriș}

Tedarik zincirlerinin bulundukları pazarda rekabet edebilme kabiliyetleri ve performansları sahip oldukları lojistik yeteneklere göre biçimlenmektedir. Günümüzde küresel bir aktör hale gelen işletmelere bakıldığında, sahip oldukları ve sürekli geliştirmeye çalıştıkları lojistik yeteneklerin bulundukları konuma gelmelerinde son derece etkili olduğu görülebilmektedir. Günümüzde sağlıklı, gerçek zamanlı ve doğru veri elde edebilme rekabet edebilmenin stratejik bir unsuru haline gelmiştir. Daha açıkçası, veri kavramı önceki yüzyıllarda ekonomik faaliyetlerin bileşeni olarak sayılan, emek, sermaye, kaynak vb. faktörlerin yanında bir üretim faktörü olarak yerini almaya başlamıştır.

Günümüzde endüstriler için üretim kararı alma, hangi ürünlerin, ne kadar ve ne zaman üretileceğine karar verme, yatırım vb. türde kararların neredeyse tamamı elde edilen

\footnotetext{
* Sorumlu yazar/Corresponding author.

e-posta: ismailiyigun@trakya.edu.tr
} 
verilere göre alınabilmektedir. Özellikle, endüstriler riskleri azaltabilmek için bu verilere büyük önem atfetmektedir. Dahası, işletmeler ve tedarik zincirleri süreçlerini optimize etmeye çalışırken tümüyle bu verileri temel alabilmektedir.

Dolayısıyla veriler tedarik zincirlerinin yapısal özelliklerini biçimlendirmede hayati düzeyde öneme sahip enstrümanlar haline gelmişlerdir.

Daha önceki dönemlerde tedarik zincirleri veri elde edebilmek için geçmiş deneyimlere ve sayısal değerlere, ek olarak da müşterilerden anket vb. yöntemlerle elde edilmiş gerçek zamanlı ve sağlıklı olduklarından her zaman bahsedilemeyen datalara gereksinim duymaktaydı.

$\mathrm{Bu}$ veriler hem son derece sınırlı bilgi vermelerinin yanı sıra, geniş ölçüde sübjektif ve gerçek zamanlı değildi. Dolayısıyla elde edildiği zaman ile karar alındığı zaman arasındaki süre içerisinde güncelliğini büyük ölçüde yitirebilmekteydi.

Bugün kullandığımız teknoloji verilerin toplanması, depolanması ve işlenmesi gibi fonksiyonları üstlenen ve her geçen gün daha da büyüyen bir sistemi endüstrilerin ve diğer alanların kullanımına sunmaktadır.

Büyük Veri dijital hale gelen hemen her unsuru veri olarak toplayan, bu verilerin kullantlabilir bilgiler haline getirilmesine olanak sağlayan bir sistem olarak tanımlanabilmektedir. Büyük Veri bugün Dünya üzerinde milyarlarca kullanıcıya sahip bir veri bankası olarak da nitelendirilebilir. Özellikle doğmasını ve gelişmesini borçlu olduğu internet sayesinde büyük veriye data sağladığının farkında olmayan milyonlarca kullanıcıdan veri toplayabilmektedir. Bireylerin doğrudan ve bilinçli olarak girdikleri verilerin dışında, kullanıcıların ziyaret ettikleri internet siteleri, ürün satın almak için göz attığı alışveriş siteleri, sosyal medyada beğenileri, gezerken cep telefonu sayesinde gönderilen konum bilgileri vb. çok sayıda data sisteme veri olarak aktarılmaktadır.

Büyük veri açısından akla gelebilecek her şey veri olabilmektedir. Örnek olarak bir 1sı kontrollü aracın içine konulacak ısı̈lçer bir sensorun sisteme göndereceği bilgiler, sistemin internete bağlı olması halinde büyük veriye de taşınabilmektedir. Dolayısıyla büyük verinin elde edebileceği veriler konusunda herhangi bir kısıt söz konusu olmamaktadır.

$\mathrm{Bu}$ veriler lojistik faaliyetlerin etkinliği ve verimliliği açsından da hayati düzeyde öneme sahiptir. Özellikle lojistik süreçlerin baş döndürücü bir karmaşıklığa ve değişkenliğe sahip pazarlarda faaliyet gösteriyor olması, müşterilerin beklentilerinin sürekli ve birden bire değişebilmesi, her an yeni bir uygulama ya da teknoloji sayesinde faaliyetlerin etkinliğini kaybetmesi ya da bütünüyle altüst olması gibi durumlar söz konusu olabilir.

Öte yandan müşterilerin daha kişisel ve özelleştirilmiş ürün ve hizmet talebinde bulunmaları sonucunda lojistik faaliyetler bu gereksinimlere cevap verebilmek üzere daha esnek ve operasyonlarını daha mikro ölçekte planlayabilir hale gelmek zorunda kalmıştır.

Bütün bu faktörler göz önüne alındığında, lojistik aktivitelerin başarılı olabilmesi için mümkün olduğunca doğru ve gerçek zamanlı veri akışına ne ölçüde gereksinim duyulduğu görülebilir. Daha da önemlisi, düzenli veri akışının gerçekleşmesi için insan faktörüne olan gereksinim ortadan kalkmaktadır. Veri toplamak için bahsedilen unsurların yanı sira sensorlar, radyo frekansları ile tanımlama sistemleri, kameralar vb. sistemler çeşitli ölçeklerde fonksiyon üstlenmektedirler.

\section{2. Önceki Çalışmalar}

$\mathrm{Bu}$ konuda çalışmalardan birisi OECD tarafindan gerçekleştirilmiş, Big Data and Transport isimli inceleme raporudur. $\mathrm{Bu}$ rapor genel olarak kentsel ulaşımı da kapsayacak şekilde taşımacılık faaliyetlerinde büyük verinin kullanımına odaklanmış, özellikle kent içi alanlarda yolculuk yapan bireylerin kullanacakları teknolojik unsur ve uygulamalar incelenmiştir(OECD 2016).

Bunun yanı sıra, Büyük Veri kavramı lojistik dışında çok farklı alanlarda gerçekleştirilen çalışmalara konu olmuş, Muhasebe ve uygulamaları (Arslan ve Özerhan 2017), deprem ve yer bilimleri (Aslan vd. 2017), ekonomi ve verimlilik (Çakırel 2016), tüketici davranışları ve pazarlama (Yapraklı ve Ünalan 2017, Altunışık 2015, Dirsehan vd. 2017), hukuk ve kişilik hakları (Çekin 2016, Eyüpoğlu vd. 2017), Kültür (Boyl et al. 2015), Eğitim (Öztürk 2017, Bozkurt 2016) ve Teknoloji (Aktaş 2017, Atalay vd. 2017) gibi çok sayıda farklı alanlarda üzerinde çalışılan bir konu haline gelmiştir.

Bunların dışında Türkiye'de doğrudan Büyük Veri ve lojistik süreçler arasındaki etkileşime ve lojistik süreçlerde meydana gelebilecek etkilere dikkat çeken bir çalışma mevcut değildir. Uluslararası çalışmalara bakıldığında, ilk olarak Zhong vd. tarafından ortaya konan çalışma dikkat çekmektedir(Zhong et al 2015). Bu çalışmada radyo frekansları ile tanımlama sistemlerinin veri toplama işlevi ile Büyük Veri arasında olan ilişsileri tanımlamış, bütüncül bir sistemin önemi vurgulanmıştır. Diğer bir çalışma Wang vd. tarafından yapılmış Büyük Veri ve tedarik süreçleri değerlendirilerek, bu alanda analitiklerin önemi vurgulanmıştır (Wang et al 2016).

Waller ise analitiklerin yanı sıra, tahminleme süreçlerinde Büyük Verinin sağlayacağı faydalara odaklanmıştır (Waller and Fawcett 2013). Son olarak, Kwon işletmelerin IT kapasite ve yeteneklerinin veri elde etmede etkisi ve Büyük Veri'nin bu konudaki rolünü analiz etmeye çalışmıştır(Kwon et al 2014). Buna ek olarak, demiryolu ile yük taşımacılığında kullanılacak sensorlar ile sevkiyat takibi, vagonların durumu vb. gibi konularla ilgili veri toplanabileceği Eaton vd. tarafından dile getirilmiştir (Eaton et al 2012).

\section{Yöntem}

Bu çalışmada tedarik zincirleri ve lojistik süreçleri ile Büyük Veri arasındaki ilişkilerin yanı sıra, Büyük Verinin bu sistemler üzerinde yaratması muhtemel etkilere odaklanılmaktadır. Bu kapsamda, mevcut durum analiz edilerek ve Büyük Veri'nin lojistik süreçlerde meydana getirdiği değişimler gözlemlenerek, gelecekte nasıl bir görünüm sergileyeceği sezgisel yaklaşım çerçevesinde analiz edilmeye çalışılmıştır. 
Çalışmanın çerçevesinde konu ile ilgili literatür taranmış, ulusal kaynakların yanı sıra uluslararası kaynaklar da gözden geçirilmiştir. Özellikle ulusal ve uluslararası veri tabanları taranarak, konuyla ilgili literatür bütünüyle gözden geçirilmiştir.

Büyük Veri ile ilgili günümüze kadar olan gelişim süreci değerlendirilmiş, başta üretim süreçleri olmak üzere tüm alanlara ilişkin meydana getirdiği değişimler gözlemlenmiştir. Çalışmanın kapsamı olarak lojistik sistemlerin ve uygulamaların gereksinimleri dikkate alınarak, Büyük Veri sisteminin meydana getirebileceği değişim ve dönüşümler öngörülmeye çalışılmış, buna ilişkin projeksiyonların ortaya konulmasına çaba gösterilmiştir.

\section{Endüstri 4.0 ve Büyük Veri}

Endüstri 4.0 süreci hayata ilişkin hemen her şeyin gerçek yaşamdan sanal evrene aktarılması, bütün nesnelerin dijital bir karakter kazanarak, katma değer yaratan bir unsura dönüşmelerini ifade eden bir yaklaşım olarak tanımlanabilmektedir. $\mathrm{Bu}$ kapsamda günlük hayata ek olarak, bütün tedarik, üretim ve dağıtım süreçlerinin ileri bir teknolojik altyap1 kazanmaları, sanal ortamlarda yönetilebilmeleri olarak da değerlendirilebilir.

Gerçekte endüstri 4.0 olarak adlandırılan dördüncü endüstri devriminin en temel unsuru teknolojidir. Bunun sayesinde geliştirilen fiziksel ve sanal unsurların tedarik zincirlerinin operasyonel anlamda mükemmelleştirilmesine ve daha etkin bir biçimde fonksiyonlarını yerine getirebilmek üzere insan faktörünü azaltacak çözümleri yaratabilmesine odaklı bir yaklaşımdır.

$\mathrm{Bu}$ süreçte en önemli kavramlardan birisi nesnelerin interneti olarak adlandırılan uygulamalardır. $\mathrm{Bu}$ yaklaşım; geçmişte insanlar arasında ve insan - makine arasında söz konusu olan etkileşiminin yerini alabileceği öngörülen makine - makine iletişimi olarak tanımlanabilir. $\mathrm{Bu}$ çerçevede kullanılan çeşitli algılama sistemleri, sensorlar, dijital kameralar ve buna ilişkin algoritmalar içeren yazılımlar nesnelerin interneti yaklaşımını giderek geliştirmektedir.

$\mathrm{Bu}$ yaklaşıma bağlı olarak, yakın bir gelecekte makineler arasında iletişimin giderek mükemmel bir nitelik kazanacağ 1 ve insan faktörünü buna bağlı olarak tedarik zinciri süreçlerinden kısmen ya da tümüyle çıkaracağı değerlendirilebilmektedir.

Makineler arası iletişim aynı zamanda makinelerin birbirini harekete geçirebilmesi ve süreçlerle ilgili optimal kararlar alarak uygulayabilmesi anlamına gelmektedir. İnsan faktörünün fiziksel faaliyetler dışında karar alma süreçleri dışına çıkarılması; otonom sistemlerin gelişimini tamamlamasına ve tedarik zincirlerinde gerçekleştirilen faaliyetlerin daha akıllı sistemler tarafından üstlenileceği değerlendirilmektedir. Bunun sonucunda akıllı tedarik sistemleri "smart supply systems, ak1llı fabrikalar "smart factories" ve akıllı lojistik uygulamalar "intelligent logistics applications" gibi yaklaşımlar gelecekte hayatın bir parçası haline gelebilecektir.

$\mathrm{Bu}$ sistemlerin otonom bir hale gelmesi ve akıllı sistemlerin gelişimi doğru, eksiksiz ve gerçek zamanlı veri akışına doğrudan bağlıdır. Bu sistemler sahip oldukları fonksiyonlar çerçevesinde süreçler ile ilgili değerlendirme yapabilmekte ve çözümleri analiz ederek, optimal kararlar alabilmektedirler. Optimize edilmiş kararlar alabilmeleri için sürekli olarak kendilerine veri sağlayan veri akış sistemlerine ihtiyaçları vardır. $\mathrm{Bu}$ veriler olmadan çözümleme yapabilmeleri ve daha mükemmel operasyonlar gerçekleştirmeleri olanak dahilinde görülmemektedir.

Geçmişte klasik türde veri toplama yöntemleri günümüzün değişim hızı dikkate alındığında, büyük oranda işlevsiz kalabilmektedir. En azından; bu yöntemler son derece sınırlı kalabildikleri gibi, elde edildikleri zaman ile karar alınma süresi arasında geçen süreye bağlı olarak güncelliklerini kaybedebilmektedirler.

$\mathrm{Bu}$ yaklaşımlardan farklı olarak, veri toplama, işleme ve analiz yeteneklerine sahip, aynı zamanda gerçek zamanlı veri sağlayabilen ve milyonlarca kullanıcıya sahip olan bir sistem bu konuda gereksinimleri karşllayabilecek ve son derece etkin çözümler yaratabilecek gibi görünmektedir.

$\mathrm{Bu}$ sistem endüstri 4.0 sürecinin de bir bileşeni olan Büyük Veri "Big Data" olarak tanımlanan sistemdir. Büyük Veri; internet sayesinde elde edilen doğrudan ve dolaylı verilerin dışında, sensorlar ve diğer ileri tanımlama sistemleri sayesinde oldukça geniş kapsamda veri toplayabilmekte, bunları çok farklı özellikleri çerçevesinde sınıflandırabilmekte ve kullanıcıların verilere erişimini sağlayarak bu tür gereksinimleri karşılayabilmektedir.

Öte yandan Büyük Veri bulut bilişim sistemleri ve internet sayesinde makineleri ve robotik sistemleri harekete geçirebilmekte, nesnelerin interneti (IoT) yaklaşımı; Büyük Veri ile elde edilen verilerin yanı sıra, fiziksel unsurlar arasında iletişim sağlanmasını olanaklı hale getirmemesi sayesinde işlevsel olabilmektedir.

\section{Lojistik ve Büyük Veri}

Üretim, tedarik vb. tüm alanlar göz önüne alındığı zaman, veri gereksiniminin en yoğun hissedildiği alanların başında lojistik gelmektedir. Bunun temel nedenlerinden birisi; lojistik faaliyetlerin üretim gibi standart ve yüksek ölçekli faaliyetleri yürütmemekte daha fazla mikro ölçekli ve son derece çeşitlenebilen faaliyetlere odaklı olmasıdır.

Günümüzde müşterilerin talepleri geçmiştekinden farklı olarak son derece kişiselleşmiş ve özel bir karaktere sahip olabilmektedir. Aynı ürünü satın alsalar bile, paketleme şekli, talep edilen ürünün miktarı vb. çok sayıda değişken beklentiler tüketici ve müşteriler tarafından tedarik zincirlerinden beklenebilmektedir. Aynı zamanda müşterilerin mağazalara gitmek yerine, giderek artan bir biçimde elektronik ortamlardan alışveriş yapmaya başlamış olmaları da bu duruma etki edebilmektedir.

Geçmişte lojistik faaliyetler ürünlerin olabildiğince yüksek miktarda ve az çeşitlilikle elleçlenmesine odaklıyken, bütün bu faktörlerin bir sonucu olarak, daha fazla sayıda ve çeşitlilikte ürünleri daha yüksek çeşitlilik çerçevesinde elleçleyebilmektedir.

$\mathrm{Bu}$ durum daha karmaşı $1 \mathrm{k}$ iş süreçleri yaratabilmekte ve lojistik faaliyetlerin sistematik bir eksende planlanması ve organizasyonunu zorlaştırmanın yanı sıra, olası riskleri de 
giderek artırmaktadır. Tedarik zincirlerinin bu problemleri aşmasının en temel yolu; müşteri gereksinimlerine mümkün olduğu kadar etkin bir biçimde cevap verebilmeyi olanaklı hale getirebilecek düzeyde esnek bir yapıya sahip olabilmeleridir.

Günümüz koşullarında gereksinim duyulan esnekliği sağlayabilecek unsurların başında lojistik akış hızını kontrol edilebilir bir biçimde artırabilecek ve süreç içerisinde çözüm alternatiflerini değerlendirerek en iyi sonucu verebilecek optimal çözümün anlık olarak belirlenebilmesi gelmektedir.

Müşterilerin her geçen gün daha hızlı bir biçimde ürünlerin kendilerine ulaştırılmasını istemelerine ek olarak, ürünlerin son derece çeşitli hale gelmesi, bu gereksinimlerin insan faktörü ile karşılanabilmesini olanaksız hale getirmektedir. $\mathrm{Bu}$ nedenle esneklik düzeyinin gereksinim duyulan seviyeye çekilebilmesi için teknoloji kullanımının artırılması, hatalara ve sistemde yavaşlamaya yol açan insan faktörünün olabildiğince azaltılması günümüz koşullarında tedarik zincirleri için hayati düzeyde öneme sahip bir gereksinim haline gelmiştir.

Söz konusu gereksinimler dikkate alındığında, Büyük Veri teknolojisinin lojistik faaliyetlerin performansı açısından yaratabileceği fayda dikkate değer bir görünüm sergilemektedir. Günümüzde lojistik faaliyetlerin etkin bir biçimde yürütülmesinde veri gereksinimin yoğun olmasına ek olarak, lojistik faaliyetler tamamlandığında ortaya çıkan sonuçların değerlendirilmesine ilişkin gereksinimlerin ve lojistik iş hacminin giderek artması da Büyük Veri uygulamalarına olan gereksinimi artırmaktadır.

Henüz yeterli düzeyde olmasa da, tedarik zincirleri ve işletmeler Büyük Veri kullanımına giderek artan bir ilgi ile yaklaşmaktadır. Bunun en temel sebeplerinden birisi sosyal medya ve diğer internet kaynaklarından günlük olarak milyonlarca $\mathrm{kB}$ veri toplanması, her geçen gün sistemde dolaşan veri miktarı artış göstermesidir. İnternette dolaşan ve toplanan verilerin \%90'ının son iki yılda toplandığı göz önüne alınırsa, söz konusu artıșın hızı daha iyi anlaşılabilir. Sadece Walmart'ın perakende sisteminde akan verinin hacmi 2,5 milyon Petabayt civarındadır (SAS Whitepaper 2012). Daha da önemlisi, endüstriler ve lojistik sistemler için müşteri olarak da değerlendirilebilen bireysel internet kullanıcıları sisteme doğrudan ve dolaylı olarak veri girişinde bulunan aktörler olduğundan elde edilen veriler büyük oranda güncel, kişisel ve doğru nitelikli bilgi ve dataları içerebilmektedir.

Büyük veri çok sayıda farlı kaynaktan toplanan devasa ölçekte verinin toplandığı bir veri bankası olarak da adlandırılabilir. $\mathrm{Bu}$ eksende sistemde yer alan verilerin büyük bölümünü yapılandırılmamış veriler oluşturmaktadır. Son süreçte çeşitli teknoloji firmalarının ve internet tarayıcılarının bu verileri yapılandırılmış, dolayısıyla kullanılabilir hale getiren bir takım sistemler tasarlamaları Büyük Veri'nin bireylerin yanı sıra işletmeler ve tedarik zincirleri tarafından kullanımını artıran bir etken olmuştur.

Büyük Veri bu sistemler sayesinde sınıflandırılmış ve kullanılabilir veriler sağlayabilmektedir. Örnek olarak belirli bir bölgede sipariş edilen ürünlere ilişkin her türlü bilgi toplanabilmekte ve işletmeler ve tedarik zincirlerinin her türlü gereksinimine göre sinıflandırılabilmektedir.
Dolayısıyla söz konusu bölge de lojistik faaliyetleri için yatırım yapmayı planlayan bir işletme tüm kararlarını bu verilere göre alabilmektedir.

Ya da internet üzerinde yer alan alışveriş sitelerine ilişkin verilerin yanı sıra, potansiyel müşterilerin sosyal medya mesajları dahil tüm hareketleri izlenerek, bir lojistik sistemde taşıma, ikmal, envanter ve dağıtım vb. türde bütün lojistik faaliyetlere ilişkin politikalar geliştirilebilmektedir. Öte yandan internet kullanımının giderek mobil bir karakter alması sonucunda cihaz adı verilen "device" cep telefonu ve tabletler sayesinde veri akışı sınırsız hale gelebilmektedir. Dolayısıyla tüketiciler belirli bir yere bağlı olmaksızın her yerden ve istedikleri zaman ürün talep edebilir hale gelmişlerdir.

Bu durum lojistik faaliyetlerin sadece belirli zamanlar içinde gerçekleştirilmesi gibi geleneksel uygulamaları da tümüyle değiştirmiştir. Geçmişte lojistik faaliyet yürüten unsurlar günün belirli saatlerinde mal kabul ve sevkiyat gibi işlemler yaparken, günümüzde ise her an lojistik operasyonlar gerçekleştirilebilmekte, müşteriler her an sipariş gönderebilmektedir. Gelecek yillarda bu durumun daha da yoğun bir hale geleceği ve lojistik operasyonların daha karmaşık bir görünüm sergileyeceği değerlendirilmektedir. Gelecek yıllara yönelik gerçekleştirilen analizler ve projeksiyonlar bu duruma kanıt olarak gösterilebilir. Buna ilişkin gerçekleştirilen bir analizde 2021 yılında cihaz sayısının daha da artacağı, birbiri ile iletişim halinde olan cihazların toplam cihazların yarısını aşacağı değerlendirilmektedir.

Şekil 1. 2016-2021 Cihaz Sayısındaki Artışlar

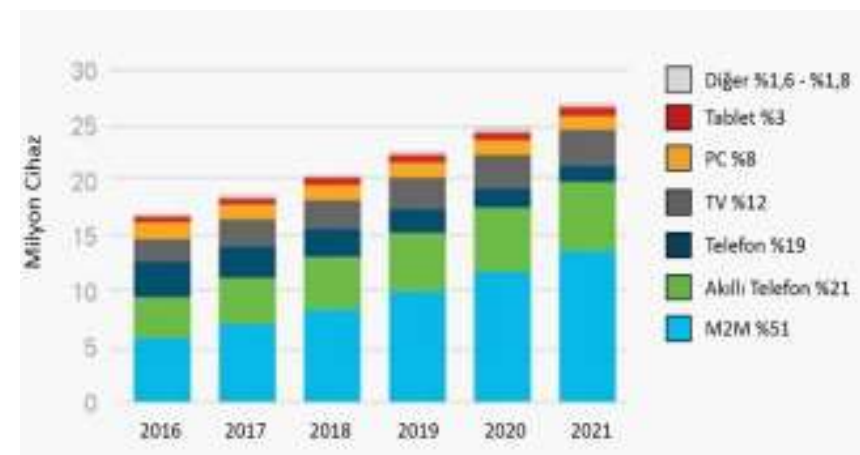

Kaynak: https://www.cisco.com

$\mathrm{Bu}$ kapsamda tedarik zincirleri sahip oldukları lojistik sistemlerini giderek daha esnek bir hale getirmenin yanı sıra, esneklik düzeyini sürekli artırabilecek çözümler bulmak zorunda kalacaklar, aksi durumda çok hızlı ve kolay bir biçimde rekabet dışı kalabileceklerdir.

Esneklik düzeyini artırabilmek için gerekli olan teknolojik uygulamalarının ve bu kapsamda Büyük Veri kullanımının lojistik işletmelere ve hizmet üreten aktörlere birçok stratejik olanaklar ve avantajlar sağlayabilme potansiyeli son derece yüksektir. 
Şekil 2. Akıllı Raf Sistemleri ve Doğrudan İkmal Uygulamaları

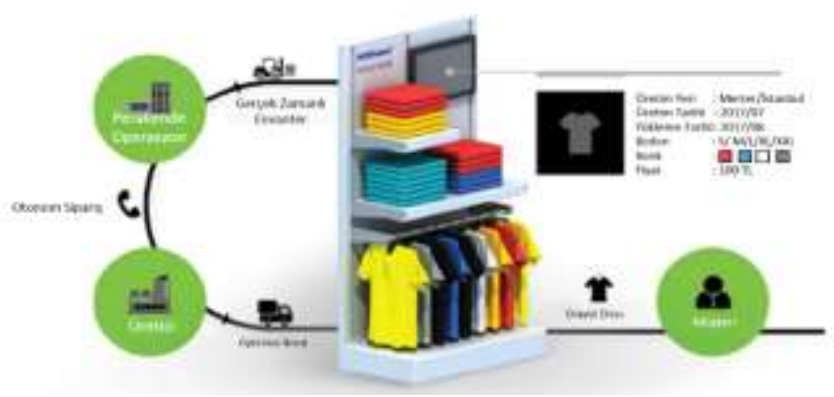

Akıllı raf sistemleri perakende süreçlerinde organize edilen ve gerçekleştirilen lojistik faaliyetleri önemli ölçüde etkilediği gibi, rafların daha etkin ve verimli bir biçimde kullanılmasına da olanak sağlamaktadır. Elde edilen veriler çerçevesinde tüketicinin ilk olarak ilgilendiği raflar katma değeri daha yüksek ve daha yoğun talep edilecek ürünlerin konulacağ1, buna karşılık müşterinin daha ilgileneceği ve önünde daha az zaman harcayacağı raflar katma değeri nispeten düşük ürünlerin konulduğu raflar olabilir. Dolayısıyla akıllı raflar daha rasyonel ve optimal bir raf yönetimi perspektifi de sağlayabilmektedir.

Raflar sayesinde edinilecek veriler raflar üzerinde yerleştirilecek RFID etiketlerinin dışında, sensorlar ve dijital kameralar sayesinde daha yoğun bir biçimde elde edilebilmektedir.

$\mathrm{Bu}$ doğrultuda raf üzerine yerleştirilecek bir 1sı ölçer sensor ile rafa yakınlaşan müşterinin vücut 1sısı değerleri ölçülerek, hangi ürünleri alacakları daha önce veriler değerlendirilerek hazırlanmış algoritma ve analizler ile tahmin edilebilir.

Aynı şekilde dijital kameralar ile müşterilerin raflar önünde sergiledikleri göz hareketleri izlenerek, genellikle hangi hareketleri sergiledikleri ölçülebilir, aynı zamanda buna bağlı olarak hangi ürünleri tercih edebileceklerine ilişkin analizler yapılabilir.

Bu sayede bazı rafların lojistik açıdan değerleri daha yüksek olabilirken, bazılarının düşük olabilmekte, dolayısıyla geçekleştirilecek operasyonların hangi rafta sonlandırılacağına ilişkin kararlar elde edilecek bu verilere uygun olarak alınabilir.

\subsection{Müşteri Konsantrasyonu ve Etkinlik}

Müşterilerin farklı koşullar altında gösterebileceği tutum ve davranışların belirlenmesi ve buna yönelik önlem ve uygulamaların önceden belirlenmesi tedarik zincirine olan güveni artırabilmektedir.

Müşterilerin önemli bir bölümü günümüzde tam olarak anlaşılamadığından şikâyet etmekte ve buna yönelik çözümler beklemektedir. $\mathrm{Bu}$ durumun sürmesi halinde tercihlerini çok kolay bir biçimde değiştirebilmektedir.
Bununla birlikte müşterilerin tutum, davranıș ve beklentilerini ölçmek üzere yapılan geleneksel yaklaşım ve metotlar günümüzün gereksinimlerine yeterli ölçüde cevap verememekte, yapıldığı andan hemen sonra güncelliğini yitirebilmektedirler.

Müşterilerin davranışları ve beklentileri çok sayıda faktör ve değişkene bağlı olarak birden bire değişim gösterebilmektedir. Dolayısıyla katma değer yaratacak bilgi ve verilerin mutlak suretle gerçek zamanlı olmaları gerekmektedir. $\mathrm{Bu}$ gereksinimlerin ancak Büyük Veri sayesinde karşılanabileceği ve tedarik zincirlerine gerçek zamanlı ve doğru bilginin bu şekilde akışının sağlanabileceği kabul edilen bir gerçektir.

$\mathrm{Bu}$ konuda karşı karşıya kalınabilecek en büyük problemlerden birisi de satış kaybı ya da stoksuzluk maliyeti adı verilen durumla karşılaşılmasıdır. $\mathrm{Bu}$ durum müşterileriler ürünleri satın almak isteseler bile envanterde ürün kalmadığı için söz konusu talebin karşılanamaması olarak ifade edilebilir. Bunun tek açıklaması olması gereken düzeyde bir planlama yapılmasına imkân sağlayacak verilerin olmaması ya da yeterli düzeyde toplanmamış olması veyahut verilerin gerçek zamanlı olmaması olabilir. Bu durum tedarik zincirleri ve işletmeler için kayda değer bir risk oluşturabilmektedir. Özellikle tedarik zincirinde hammaddeden başlayarak ürüne kadar olan akış süreçlerinin uzun olduğu sistemlerde müşteri taleplerine anlık olarak cevap verilememesi halinde bu sürecin işletilerek talebin karşılanmaya çalışılması olanaksız hatta imkânsız olabilmektedir. Daha da önemlisi müşteri toleransı akış sisteminin süresinden daha kısa ise müşteriler taleplerinden çok kısa zaman içinde vazgeçebilmektedir.

$\mathrm{Bu}$ problemi çözmenin en temel yollarından birisi müşteri davranış ve tutumlarını biçimlendiren değişkenlerin ve faktörlerin neler olduğunun belirlenmesi ve bu verilerin sürekli olarak güncel bir biçimde elde edinilebilmesidir.

Geleneksel tahminleme yöntemleri daha önce bahsi geçen kısit ve sinırlılıklardan dolayı bu gereksinimleri karşılamaktan uzaktır. İstatistiki yöntemler ya da kalitatif araştırmalar sonucu elde edilen verilere dayalı olarak alınan kararlarda önemli ölçüde sapmaların görülebilme olasılığ son derece yüksek olabilmektedir.

Dolayısıyla anlık verilerin toplanarak, işlendiği ve mevcut durumlara ilişkin en iyi çözümün belirlendiği Büyük Veri gibi sistemler bu problemin çözümünde son derece etkili olabilir. Büyük Veri sayesinde daha önce edinilmiş çok yüksek ölçekte verilerin işlenmesi sayesinde oluşturulmuş algoritmalar insan faktörü ile kıyaslandığı zaman daha optimal çözüm ve yöntemler önerebilir. Bu sistem tedarik zincirinin müşterilerinden her zaman bir adım önde olmasına olanak sağlamakta, çözüm bulabilmek için tedarik zincirine zaman kazandırabilmektedir.

\subsection{Lojistikte Yeni Eğilimler ve Büyük Veri}

Büyük Veri yaklaşımı tedarik zinciri ve lojistik süreçlerde yeni perspektiflerin ortaya konulmasına ve farklı türde yaklaşımlar geliştirilmesine olanak sağlayabilme potansiyeline sahiptir. 
Müșterilerin çeşitli elektronik unsurlar kullanarak, dijital evrende ayak izi bırakmaları bu ayak izleri takip edilerek, müşterilerin gereksinimlerini olabilecek en etkin bir biçimde karşılayabilecek son derece yaratıcı çözümlerin belirlenmesine ortam hazırlayabilir.

Örnek olarak, müşterilerin sahip oldukları cihazlar müşterilerden bağımsız olarak sürekli olarak Büyük Veri’ye farklı nitelikte veriler gönderebilmektedir. Bunun en bilinenlerinden birisi konum bilgisidir. Müşteriler cep telefonları ve tabletleri ile internete bağlı olsunlar ya da olmasınlar sürekli olarak konum paylaşımı yapabilmektedirler.

Büyük Veri tarafından alınan bu veriler, verinin gönderildiği konuma ilişkin başka türlü verileri de toplayarak bunlar sayesinde müşterilerine özel kişisel bir takım uygulamalar geliştirebilir. Örnek olarak konum bilgisi alan sistem söz konusu ortamın sıcaklığı ve nem değerlerini tespit ederek, ekstrem koşullarda müşterilere soğuk içecek reklamı gönderirken eş zamanlı olarak tedarikçilere bununla ilgili ürünlerin ikmal işlemleri için komutlar da gönderebilmektedir.

Dolayısıyla tedarik zincirleri tüm lojistik operasyon ve uygulamaları mikro ölçekte yapılandırılabileceği gibi, aynı zamanda göz alıcı bir esneklik düzeyine ulaşılabilmeleri mümkün olabilmektedir.

\section{Lojistik Süreçlerde Büyük Veri Uygulamaları}

Lojistik faaliyetler giderek daha teknoloji yoğun hale gelmenin yanı sıra, bütün uygulama ve süreçlerini geleneksel olarak sezgisel bir yaklaşımla değil, veri ve bilgilere dayalı olarak gerçekleştirme eğilimi göstermektedir. Geçmişte olduğundan daha yoğun bir biçimde lojistik faaliyetlerin etkinlik ve verimlilik perspektifine odaklanmaları, bu amaca uygun olarak bir takım yeni uygulama ve metodoloji geliştirmeye çalışmaları dikkat çeken bir durum olarak değerlendirilebilir.

Bununla birlikte Büyük Veri analitiklerinin kullanımı konusunda lojistik faaliyetlerin henüz kendisinden beklenen düzeye erişemediği de söylenebilir. Bunun en temel nedenlerinden birisi müşteri tutum, davranış ve beklentilerinin son derece değişken olmasının yanı sıra, bunlara etki eden faktörlerin de dikkate değer ölçüde değişkenlik düzeylerinin yüksek olması olarak gösterilebilir.

Dolayısıyla Büyük Veri analitiklerinin kullanımı yeni başlayan bir yaklaşım olsa da giderek artan bir hızla gelişim göstermekte, gelecekte çok yüksek hacme ulaşacağ değerlendirilmektedir.

Büyük Veri ile ilgili potansiyele değerlendirilmek istendiğinde lojistik sistemlerin gereksinimlerine göz atmak gelecek dönemlerle ilgili projeksiyon yapmak için yeterli olabilecektir.

Lojistik faaliyetler daha önce bahsedilen değişken koşul ve durumlarla baş etmek zorunda olduğundan bu problemlerin çözümü için doğru, eksiksiz ve gerçek zamanlı veri akışına hemen her sektörden daha fazla gereksinim duymaktadır.

Büyük Veri bu kapsamda olabildiğince yoğun ve geniş ölçekli veriyi mümkün olan en mikro düzeyde sağlayabildiği için, her bir müşteri için farklı çözüm ve yaklaşımların geliştirilmesi olanaklı olabilmekte, tedarik zincirleri buna bağlı olarak geçmişte olmadığı kadar esnek bir yapıya sahip olabilmektedir.

Bu sayede müşteri sadakatini artırabilmekte ve toplam fayda ile birlikte elde edilen katma değerin artmasına olanak sağlayabilmektedir. Daha da önemlisi kaynaklar ile karşılanan gereksinimlerin dengelenmesi çerçevesinde daha düşük kaynak kullanımı ile daha yüksek düzeyde müşteri ihtiyaç ve taleplerinin karşılanabilmesini mümkün hale getirebilmektedir.

Büyük Veri lojistik faaliyetler açısından yüksek düzeyde rekabet olanağı ve stratejik olarak süreçleri daha iyi yönetebilme olanağı sağlamasının yanı sıra, her bir tedarik zincirinin farklı yapıya ve işleyişe sahip olduğu unutulmamalıdır. Dolayısıyla Büyük Veri analitiklerinin operasyonlarda kullanılmasına başlanmadan önce bu verilerin nasıl kullanılacağı ile ilgili bir yol haritasının hazırlanması gerekmektedir. Öncelikli olarak, karar alıcıların ulaşmak istedikleri hedefleri belirlemeleri ve bu hedeflere ulaşılmasına yönelik gereksinim duyacakları verilerin neler olduğunu saptamaları gerekmektedir.

Büyük Veri sistemi yapılandırılmamış bir sistem olduğundan içerisinde yer alan her veri lojistik faaliyetlerin planlanması ve yürütülebilmesi için kullanılabilecek veriler olmayabilir. Bu nedenle hangi verilere gereksinimin olduğu ve bunlardan hangilerinin seçilmesi ve işlenmesinin gerekli olacağı önceden belirlenmelidir.

Büyük Veri lojistik faaliyetlerin veri gereksinimlerini büyük ölçüde giderebileceği ve lojistik faaliyetlerin neredeyse bütününü kapsayacak şekilde kayda değer iyileştirmeler sağlayabilme olanağına sahip olduğu görülmektedir. Bununla birlikte her bir operasyon için ayrı ayrı değerlendirme yapıldığında Büyük Veri tarafindan sağlanacak faydalar ve stratejik avantajlar daha iyi anlaşılabilir.

\subsection{Taşıma ve Dağıtım}

Taşıma ve dağıtım faaliyetleri bir tedarik zincirinde en yoğun maliyet yaratmasına karşılık yüksek katma değer yaratmayan lojistik uygulamalar olarak gösterilebilir. $\mathrm{Bu}$ nedenle bu faaliyetlerde elde edilecek bir birim iyileştirme bile, maliyetleri büyük oranda azaltabilmekte, elde edilecek toplam katma değeri artırabilmektedir.

Dolayısıyla bir dağıtım ya da taşıma operasyonunda diğer faktörler sabit kalmak koşuluyla ne kadar yüksek düzeyde ürün taşınabilirse verimlilik o kadar yüksek olabilmektedir.

Özellikle dağıtım süreçlerinde bunun en etkin yolu her birim kilometre için taşınabilecek en yüksek miktarda yükün taşınabilmesidir. Bu nedenle bir dağıtım aracı ne kadar fazla noktaya uğrayarak ürün birakabilirse operasyon tamamlandığında o kadar fazla dağıtım yapabilmekte, birim başına düşen lojistik maliyet azalabilmektedir.

Geleneksel yaklaşım çerçevesinde dağıtım faaliyeti yeterli ölçüde verimlilik sağlayamamaktadır. Bunun en temel nedenlerinin başında; planlamanın sürecin en başında yapılması, zaman içerisinde bir takım değişiklikler söz 
konusu olsa da bunların dikkate alınmaması ve operasyonun planlandığı şekilde tamamlanmasıdır.

$\mathrm{Bu}$ durumda her şey yolunda gitse bile planlanan düzeyin üzerinde lojistik faaliyetin ölçek olarak artırılması olanaklı olmamaktadır. Daha da önemlisi, anlık siparişlere kolay bir şekilde cevap verilemediği gibi, zaman zaman ortaya çıkan bir takım aksaklıklar sonucunda planlanan iş hacminden negatif yönde sapmalar görülebilmektedir. Trafik sıkışıklığı sonucu geç ulaşılan bir perakendecinin mal kabul zamanı dolduğu için ürünü teslim almaması ya da çeşitli gerekçeler ile geri çevirmesi planlanan iş hacminde azalmalara yol açabilmekte, sonu olarak elde edilen toplam verimlilik azalım göstermektedir.

Büyük veri sayesinde dağıtım aracı yola çıktıktan sonra bile, planlarda birçok değişiklik ve güncelleme yapmak mümkün olabilmektedir. örnek olarak, planda yer almayan bir müşteri acil bir sipariş geçtiği zaman planlarda buna ilişkin revizyon yapılması mümkün olabilmekte, mal kabul saati dolmak üzere olan bir perakendeciye yapılacak teslimat aciliyet durumu düşük olan diğer perakendecilere göre daha öne alınabilmektedir.

Büyük veri sayesinde anlık durum değişikliklerinin tespit edilebilir olması, değişen her duruma uygun çözümlerin geliştirilmesini mümkün hale getirebilir. Dolayısıyla bu tür lojistik süreçlerde karşılanan talep düzeyi artarken, kaynak kullanımı sabit kalmakta, bunun sonucunda birim ürün başına düşen maliyet azalabilmektedir. Ek olarak elde bulunan dağıtım, araç, işgücü ve ekipman kapasitesinin maksimum seviyede kullanılmasına da imkân taniyabilmektedir.

Büyük Veri tarafından sağlanan bir diğer avantaj ise; güzergâh optimizasyonunu sağlamanın yanı sıra, bunun değişen koşullara göre her an değişebilmesi ve güncellenebilmesine olanak sağlayacak verilere ilişkin gereksinimlerin karşılanabilmesidir.

Operasyon için seçilecek güzergâhın en iyilenmesi; hedef nokta ya da noktalara en kısa ve en uygun koşulları sağlayan yolun seçilerek, enerji tüketimi başta olmak üzere birçok maliyetin azaltılmasına olanak sağlaması ile birlikte, zaman kaybını en aza indirebilecek çözümleri ortaya koyabilmektedir.

Geleneksel düzeyde güzergâh planlama farklı çok sayıda matematiksel yöntem ve model kullanılarak değişken olmayan ya da değişkenlik düzeyi son derece düşük parametrelerin hesaba katılmasıyla yapılabilirken, statik bir nitelik göstermektedir.

Daha da önemlisi anlık değişimlere ilişkin bir çözüm yaratamadığından planlar ile gerçekleşen durum arasında sapmaların görülebilme olasılığı yüksek olabilmektedir.

Büyük Veri geleneksel matematiksel optimizasyon yöntemlerinden farklı metodolojiler ve uygulamalar getirmemekle birlikte bu yöntemler sayesinde sürekli işlenebilecek veri akışını sağlamakta, bunun sayesinde her an optimizasyon değişebilmekte ve daha iyi çözümler elde edilebilmektedir.

Müşterilerin yeni gelen siparişleri ya da tedarik zinciri tarafindan plan dışı komutlar dışında anlık trafik verileri de güzergâh optimizasyonu için veri olarak kullanılabilmektedir. Örnek olarak, planda söz konusu an için en iyi ulaşım imkânı belirli bir yol üzerinden belirlenmiş olmasına rağmen, gün içinde değişen koşullara bağlı olarak, sistem yani rotalar hesaplayabilmekte ve belirleyebilmektedir.

Uygulamada hesaplamayı yapan unsurlar yine bahsi geçen matematiksel modellerken, Büyük Veri sağlanan veri miktarını ve tekrarlama sayısını büyük ölçüde artırarak, bu sistemler sayesinde her bir operasyon için başlangıçta bir kez hesaplama yapılmasına karşılık, anlık olarak sonsuz sayıda hesaplama işlemi yapabilmelerini olanaklı hale getirecek şekilde veri sağlama fonksiyonunu yerine getirmektedir. Dolayısıyla matematiksel modellerin dinamik bir karakter kazanmalarına etki eden en temel unsurların başında Büyük Veri gelmektedir.

Taşıma ve dağıtım süreçlerinde bir başka problem ise taşınan ürünlerin çeşitliliği ve çok sayıda farklı noktaya taşınmalarıdır. Bu durum dağıtım süreçlerinde verimliliği ve etkinliği büyük ölçüde etkileyebilmekte katlanılan maliyetleri artırabilmektedir. Büyük Veri eş zamanlı olarak çok sayıda değişkeni analiz ederek gerçekleştirilen optimizasyon sayısını birim zaman içerisinde sürekli hale getirebilecek verileri gerçek zamanlı sağladığından, mümkün olabilecek en üst düzeyde verimlilik düzeyinde dağıtım ve taşımacılık operasyonunun gerçekleştirme olasılığını son derece artırabilmektedir.

Bunun yanı sıra, müşteriler herhangi bir nedenle siparişlerini iptal edebilmekte ya da ertelenmesini talep edebilmektedirler. $\mathrm{Bu}$ durumda dağıtım unsurları ilk anda gerçekleştirdikleri plana sadık bir biçimde hareket ettiklerinde teslimat yapamadan uzun bir güzergâhı kat etmiş olabilirler. Buna karşılık, bu tür verilerin sistemde sürekli olarak akması ve her an değişen durumlara göre planların güncellenebilir olması, gereksiz iş süreçlerinin dağıtım ve taşıma operasyonlarından çıkarılmasını ve daha sonraya ertelenmesini olanaklı hale getirmektedir.

Bir lojistik sistemde kaynakların etkin ve verimli bir biçimde kullanılması son derece önem arz eden yaklaşımların başında gelmektedir. Müşterilere arz edilen kapasitenin yetersiz olması müşteri sadakat ve memnuniyetini azaltırken, yüksek olması ile beraber katlanılan maliyetler de artabilmektedir. $\mathrm{Bu}$ nedenle kaynaklar ile müşterilere arz edilen hizmetler arasında bir dengenin kurulması gerekli olmaktadır. Her iki durum tedarik zincirinin verim ve etkinlik düzeyinin olumsuz etkilenmesine, dolayısı ile pazarda rekabet gücünü kaybetmesine yol açabilmektedir.

Aynı zamanda kaynak planlama durağan değil, dinamik bir karaktere sahip olmalı ve değişen durum ve koşullara uygun olarak değişim gösterebilmelidir. Bu durum ancak sağlıklı veri akışı ve işlenmesi ile birlikte bu verilerin lojistik uygulamalarda gerçek zamanlı olarak kullanılması sayesinde mümkün olabilmektedir.

\subsection{Depolama Uygulamaları}

Depolama faaliyetleri lojistik süreçlerin en önemli bileşenlerinden birisidir. Bu süreçlerde de taşıma ve dağıtım operasyonlarında olduğu gibi veri ihtiyacı son derece yüksektir. Verilerin sağlıklı ve gerçek zamanlı olması depo 
faaliyetlerinin verimliliğini ve etkinliğini doğrudan biçimlendirebilmektedir.

Depo faaliyetleri yapısal olarak çok yüksek miktar ve hacimde materyalin depolandığı süreçlerdir. Depo sahasında bir materyalin kalma süresi katlanılacak maliyetlerin artmasına da yol açabilmektedir. Statik karakterde bir hesaplama ve optimizasyon yaklaşımı başlangıçta iyi sonuçlar verebilse de kullanılan veri ve bilgilerin zamanla güncelliğini kaybetmesi ile beraber elde edilen sonuçlar ile hedeflenen sonuçlar arasında giderek sapmaların meydana gelebilmesi kaçınılmaz olabilmektedir.

Örnek olarak birçok parametre ile ilişkilendirilmiş ve buna göre mal kabul işlemi yapılmış bir depolama sürecinde ilerleyen zaman içerisinde talepler ve diğer değişkenlerde farklılaşmalar söz konusu olabilmekte, depo içerisinde bulunan materyalin sağladığı katma değer hızla azalabilmektedir.

$\mathrm{Bu}$ problemin giderilebilmesi ve mümkün olduğunca depolama hizmetinin hacminin azaltılabilmesi veri akışının sorunsuz, hızlı ve gerçek zamanlı olmasına bağlı olarak mümkün hale getirilebilmektedir. Büyük Veri sayesinde bir ürüne olan talebin artacağını görerek, envanterin artırılması ve depo süreçlerinin bu ürüne ilişkin geliştirilmesi, aynı şekilde talebi azalacak bir ürünün Büyük Veri sayesinde tespit edilmesi ve depo işlemlerinin giderek azaltılması ve depoya kabul edilen ürün miktarının düşürülmesi elde edilebilecek toplam verimliliği ve etkinliği önemli ölçüde artırabilecektir.

$\mathrm{Bu}$ kapsamda kaynak planlaması ve kullanımının depo faaliyetleri içinde optimize edilmesi ve bu işlemin değişen koşullara göre tekrarlama sıklığının artırılabilmesi kaynak verimliliğini artırabilecek bir yaklaşım olabilir.

\section{Sonuç ve Değerlendirme}

Büyük Veri tedarik zincirlerinin tüm süreçlerine ek olarak lojistik faaliyetler açısından son derece etkin sonuçlar ortaya koyabilecek potansiyele sahip teknolojik bir gelişme olarak değerlendirilebilir.

Tedarik zincirlerinin lojistik süreçler açısından gereksinim duyduğu esneklik, çeviklik ve değişen durumlara anlık olarak cevap verebilme kabiliyeti düzenli, sağlıklı ve gerçek zamanlı veri akışına büyük oranda bağımlı görünmektedir.

$\mathrm{Bu}$ yaklaşım geleneksel lojistik faaliyetlerin yerini giderek daha yüksek teknoloji kullanımının söz konusu olduğu ve farklı iş modellerine sahip lojistik uygulamaların alması sonucunu da ortaya çıkarırken lojistik faaliyetler dinamik bir karaktere sahip olma konusunda daha fazla ilerleme göstereceğini ortaya koymaktadır. Tedarik zincirleri ve işletmeler bütün faaliyetlerinin yanı sıra, lojistik uygulamalarını daha yüksek düzeyde teknoloji kullanımına dayandırmak zorunda kalmaktadır. Dolayısıyla tedarik zincirlerinin gösterecekleri performans düzeyi ile teknoloji kullanım düzeyleri arasında yakın bir ilişkinin bulunmakta, bu ilişki gün geçtikçe daha fazla belirginleşmektedir. Büyük Veri tedarik zincirlerine lojistik faaliyetlerini optimize etmek için gereksinim duydukları verileri yoğun bir biçimde sağlamanın dışında, bu veri akışlarını sürekli hale getirerek, değişen her koşula göre anlık optimizasyon yapabilmelerine ve her duruma karşı daha iyi pozisyon alabilmelerine olanak sağlayabilecektir.

Bunun sonucunda tedarik zincirleri lojistik faaliyetlerinde kendilerine makro ya da mikro ölçekte maliyet yaratan ve verimlilik ve etkinliğini azaltan tüm süreçleri elimine edebilme olanağına sahip olabileceklerdir.

\section{Kaynakça}

Aslan, Ü. Özerhan, Y., (2017). Big Data and Accounting Profession. Muhasebe Bilim Dünyast Dergisi, 19(4): 862-883.

Arslan, G. Fawzy, D., Atay, C., (2017). On The Prediction of Structural Reactions to Big Earthquakes in Turkey. Press Academia Procedia, 5(1): 335-340.

Çakırel, Y. (2016). İşletmelerde Büyük Veri. Kırklareli Üniversitesi İktisadi ve İdari Bilimler Fakültesi Dergisi, 5(1): 52-62.

Yaprakli, T. Unalan, M., (2017). Consumer Privacy in The Era of Big Data: A Survey of Smartphone Users' Concerns. Press Academia Procedia, 4(1): 1-10.

Cekin, M. (2016). An Analyze of the New Turkish Code On the Protection of Personal Data Nr. 6698 Regarding Big Data and Freedom of Will. Ístanbul Üniversitesi Hukuk Fakültesi Mecmuasl, 74(2): 629-644.

Eyüpoğlu, C., Aydin, M., Sertbaş, A., Zaim, A., Öneş, O. (2017). Büyük Veride Kişi Mahremiyetinin Korunması. Bilişim Teknolojileri Dergisi, 10(2): 177-184.

Öztürk, A. (2017). Yükseköğretimde Büyük Veri ve Öğrenme Analitikleri: Güncel Teori ve Uygulamalar. Açıkögretim Uygulamaları ve Araştırmaları Dergisi, 3(1): 218-228.

Bozkurt, A. (2016). Öğrenme Analitiği: E-Öğrenme, Büyük Veri ve Bireyselleştirilmiş Öğrenme. Açıöŏgretim Uygulamaları ve Araştırmaları Dergisi, 2(4): 55-81.

Dirsehan, T., Köse, N., Ercevik, E., Ceylan, S. (2017). Konaklama Sektöründe Büyük Veri Aracılığıyla Sektörel Rekabette Kültürel Farklılıkların Keşfi. Marmara Business Review, 2(1): 71-82.

Boyd, D., Crawford, K., Savc1, B. (2015). Büyük Veri Üzerine Eleştirel Sorular: Kültürel, Teknolojik ve Bilimsel Bir Olgu Hakkında Eleştirel Sorgulamalar. Folklor/Edebiyat, 83: 199-215.

Aktaş, M. (2017). A Software Architecture for Monitoring Big Data Storage Platforms. Pamukkale Üniversitesi Mühendislik Bilimleri Dergisi, 23(5): 597-601.

Atalay, M., Çelik, E. (2017). Büyük Veri Analizinde Yapay Zekâ Ve Makine Öğrenmesi Uygulamalari - Artificial Intelligence and Machine Learning Applications in Big Data Analysis. Mehmet Akif Ersoy Üniversitesi Sosyal Bilimler Enstitüsü Dergisi, 9(22): 155-172. 
Wang, G., Gunasekaran, A., Ngai, E. W.T., Papadopoulos, T. (2016). Big Data Analytics İn Logistics and Supply Chain Management: Certain Investigations for Research and Applications. Int. J. Production Economics, 176: 98110 .

Kwon, O., Lee, N., Shin, B. (2014). Data Quality Management, Data Usage Experience and Acquisition Intention of Big Data Analytics. International Journal of Information Management, 34: 378-394.

Waller, M. A. Fawcett, S. E. (2013). Click Here for a Data Scientist: Big Data, Predictive Analytics, and Theory Development in the Era of a Maker Movement Supply Chain. Journal of Business Logistics, 34(4): 249-252.

Zhong, R. Y., Huang, G. Q., Lan, S., Dai, Q.Y., Xu, C., Zhang, T. (2015). A Big Data Approach for Logistics Trajectory Discovery from RFID-Enabled Production Data. Int. J. Production Economics, 165: 260,272.
OECD, Directorate for Financial and Enterprise Affairs Competition Committee, (2016). Big Data: Bringing Competition Policy to The Digital Era, https://one.oecd.org/document/DAF/COMP(2016)14/en /pdf, (22.01.2017)

Eaton, C., deRoos D., Lapis, G., Zikopoulos, P., Deutsch, T. (2012). Understanding Big Data: Analytics for Enterprise Class Hadoop and Streaming Data. New York: Mc Graw Hill.

SAS Whitepaper (2012). Big Data Meets Big Data Analytics: Three Key Technologies for Extracting RealTime Business Value from the Big Data That Threatens to Overwhelm Traditional Computing Architectures.

Smart, B. D. (1999). Topgrading. Upper Saddle River, New Jersey: Prentice-Hall. 